\title{
Architectural lighting design: A research review over fifty years
}

\author{
KP Mansfield PhD FSLL
}

UCL Institute for Environmental Design and Engineering, The Bartlett

Faculty of the Built Environment, London, UK

Short title: Architectural lighting design

Received 27 June 2017; Revised 24 August 2017; Accepted 21 September 2017

Architectural developments over the past fifty years have been dramatic and have been paralleled by active research in lighting. This review traces architectural themes and the corresponding concerns of lighting researchers and explores how they have applied the results of scientific research into lighting design and application.

Address for correspondence: Kevin Mansfield, UCL Institute for Environmental Design and Engineering, The Bartlett Faculty of the Built Environment, London, UK.

E-mail: kevin.mansfield@ucl.ac.uk

\section{Introduction}

Over the last fifty years a variety of buildings have been designed and erected all of which provide different interior conditions for people to experience. Architecture is a problem of construction and its resulting form depends upon the architectural elements and materials available at the time, the formal constraints due to the site and the requirements of the users. Such architecture encloses and defines space and automatically harnesses and responds to daylight. A lit space or a series of lit spaces is created through which people move and objects and surfaces are revealed. These buildings do not exist in 
isolation - they become part of the fabric of our towns and cities. This urban extent is revealed in daylight and needs to be lit at night.

To emphasise or alter architecture, lighting technology is deployed to reinforce the daylighting or to change the purpose or the mood or the atmosphere of the building at night. The ability of the architect or lighting designer to manipulate light in this way has a profound effect in creating engaging, exciting, pleasant or sombre environments. The process by which this is undertaken has been reflected in the papers published over the long history of Lighting Research and Technology and the lighting design approaches and application techniques that have been suggested have mirrored the architectural developments of the time.

My task here is to survey these papers, to indicate any emerging themes and to give the architectural context within which these themes were developed. Tools, technologies and design approaches have changed as lighting technology has developed and lighting researchers have been interested in applying the results of scientific research to lighting design and application. A highly significant factor has been the rise of powerful computing power and its incorporation into the architectural design process. It will be interesting to see how the concerns of those involved in lighting research actually mapped against the current architectural developments of the time.

\section{Emerging post modernism}

From the 1950s to the 1960s, designing for daylight was given importance. Large amounts of fenestration was welcomed giving higher illuminances and good views but problems of uncomfortable glare and overheating emerged. By the 1970s small windows and the resulting gloomy interiors were becoming the norm.

Lighting Research and Technology was first published in 1969. Social concerns in residential architecture were to the fore where, for example in Ralph Erskine's Byker Wall in Newcastle (1969-1975), there was an attempt to create a building complex that responded to the needs of the users - to foster a sense of community. One face of the huge block turned its back on a nearby motorway and the other facade comprised small domestic-scale brick and trellis timber balconies.

The ideas of Robert Venturi, outlined in his book Complexity and Contradiction in Architecture (1966, 1977), expressed the notion of the 'decorated shed' in which the semiotics of decoration were applied to functional facades. It was a reaction against the

"...puritanically moral language..."1 of the International Style and led to the emergence of Post Modernism, championed by the architectural theorist Charles Jencks.

James Stirling in his signature buildings at the University of Leicester (Engineering, 1964) (Figure 1) and the University of Cambridge (History Faculty, 1968) was exploring Neo Constructivist architectural forms employing standardised industrial glazing and brick and tile, still admired by many in spite of their technical problems. ${ }^{2}$ In a 
lecture delivered to the Royal Institute of British Architects (RIBA) in March 1965, Stirling declared:

"Architecture has nothing to do with style or appearance, but with an organisation of functions and a facilitating of movement. Its goal is to raise the human spirit."

The concern of the lighting research community was an "environmental approach" and it seems strange that researchers were looking at the effects of small window areas and 'windowless' environments when Stirling was remarking:

"Glass buildings are appropriate in the English climate."4

But researchers were also interested in overturning the uniformity of lighting provision to avoid mediocrity and encouraging more variety in lighting.

\section{Services on the outside}

The massing of domestic developments in the regeneration of urban fabrics was the subject of renewed interest. Contrast the titanic apartment blocks in France such as Les Arcades du Lac (1975-1981) and the Palace of Abraxas (1978-1983) by Ricardo Bofill with the coastal residential development in Florida (1981) designed by Andres Duany and Elizabeth Plater-Zyberk based on local traditions with zoning laws to create comprehensible streets and squares.

The work of Glenn Murcutt at this time was interesting in that, using a limited palette of industrial materials - corrugated sheeting, louvres, screens - he designed buildings that were extruded in section and responded to the environmental characteristics of the site. ${ }^{5}$ This typological approach of toplit circulation zones and curved roof forms opening up to daylight is also shown in the characteristic environmentally responsive school architecture that flourished under Colin Stansfield Smith at Hampshire County Council.

Renzo Piano and Richard Rogers, at the Centre Pompidou in Paris (1976), redefined what a museum/gallery could be with the bold expression of mechanical services on the exterior ${ }^{6}$ and in the Lloyd's Building (1978-1986), Rogers reversed the 
traditional pattern, exposing the service exoskeleton on the outside allowing an

uninterrupted office floor.

Jean Nouvel at L'Institute du Monde Arabe, Paris (1981-1987) (Figure 2)

demonstrated how a facade could dynamically respond to a change in environment by the use of motorised iris-like shutters. ${ }^{7}$

Zoning incentives in New York City encouraged developers to provide groundlevel amenities (such as pedestrian access, enclosed atria and retail) at the base of major buildings. ${ }^{8}$ Examples included Trump Tower (Der Scutt, Swanke, Hayden and Connell (1984)), the $A T \& T$ building (Johnson and Burgee (1984)) crowned by a post modernist broken pediment and the CitiCorp building (Stubbins (1974-1977)).

In lighting terms, energy saving was important - exploring the opportunity to displace electric light with daylighting and trying to reduce overall lighting levels by controlling contrast or providing local lighting.

\section{Contextual concerns}

In the residential sector interest was shown in integrating new developments into the existing urban grain, for example, Quinlan Terry at Richmond Riverside (1984-1989) and the young disciples of Léon Krier undertaking sympathetic redevelopment in Brussels (1989-1994). In Potsdamer Platz in Berlin, a wasteland on the line between East and West, urban planners were challenged to build a new city centre in the middle of a fully developed urban structure (Figure 3). Signature architects including Renzo Piano, Norman Foster and Helmut Jahn designed individual office towers to revitalise Berlin within the context of an overall masterplan. ${ }^{9}$

This was also shown in the museum and exhibitions sector where context was everything - how do you set the modern against the old? So in Nîmes, Norman Foster juxtaposed a high-tech médiathèque against the ancient Roman Maison Carré; Robert Venturi unwrapped a 'fragmented classicism' ${ }^{10}$ for the extension of the Sainsbury Wing of the National Gallery (1987-1991) and IM Pei inserted a modern 70-foot high glass pyramid into the historic courtyard of The Louvre (1983-1989). Foster made a further intervention in redeveloping the German Reichstag (1993) comprising an inverted mirrored cone ('light sculptor') to reflect light downward. ${ }^{11}$ More optical contrivances were inserted into Foster's Hong Kong and Shanghai Bank (1986) ${ }^{12}$ where a computercontrolled heliodon at the top of the building redirected daylight into the interior.

In the lighting community there was much interest in what at first were called 'innovative daylighting' techniques and latterly 'redirecting' lighting.

\section{Computational architecture}


At the turn of the century we see regeneration in architecture - and on a huge scale — with the regeneration of the port areas in Amsterdam by Map Arq and MvRdV (and also Christian de Portzamparc in Almere). ${ }^{13}$ Steven Holl showed how in a huge development of a "...seemingly endless grid of windows"14 (Simmons Hall dormitory, MIT, Cambridge, MA (2002)) you could introduce daylight deep into the interior. William Alsop and Jan Störmer, in a building of great technological daring, designed a civic building in Marseilles (1994), nicknamed 'Le Grand Bleu', with an aerofoil shape in section and with mobile sun-shades. ${ }^{15}$

Signature buildings at this time were Herzog and de Meuron at Tate Modern in London and Frank Gehry's Guggenheim Museum in Bilbao (1997) (Figure 4) with the "...sculptural effect of daylight and sunlight on the curvilinear forms." ${ }^{16}$ The distinctive grey titanium panels had been designed using software from the aerospace industry. ${ }^{17}$ Foster + Partners iconic Swiss Re building (the 'Gherkin' (2004)) — the triangulated glass skin is in a sense generated by computation - was essentially the built reality of an algorithm.

In lighting there was an enthusiasm for the prospects of employing advanced software for visualisation but little agreement on whether you should be creating harmonious luminance patterns or revealing form using vector methods. In the gallery and museum environment, the tension between the demands of conservation and the lighting conditions needed for display were being explored.

\section{The brand}

The trend now is for huge urban masterplans overseen by one architect with other specialists contributing. Examples are the work of MvRdV in Lyons (2010) and huge urban developments in China (for example Lingang New City near Shanghai). ${ }^{18}$ Rem Koolhaas' CCTV Headquarters in Beijing (Figure 5) is so huge that it is almost a city in itself. $^{19}$

Foster's Hearst Tower, in New York City (2006), continues his technological supremacy, capping a six-storey Art Deco building of 1926-1927 with a triangularframed steel cage exhibiting claimed 'green' credentials. ${ }^{20}$ Piano's "...shard of glass..." The Shard at London Bridge (2009-2012) — has angled panels of glass to catch the light.

In lighting there is interest in circadian lighting to encourage sufficient light to promote circadian stimulation and the use of light to promote brand - a brand is now promoted through its building but also through its logo, its website and its Facebook page. Lighting designers are being exhorted to move towards the "...the third stage of the lighting profession." 


\section{Variety in lighting}

The great debate at the beginning of the 1970s was whether to allow daylight into buildings at all. The architects of the Calouste Gulbenkian Museum in Lisbon wished to assure "sensitive viewers" that museum objects were being displayed in light that did not distort their colours. They also thought that windows could "relieve the sense of total enclosure". ${ }^{21}$ However Ne'eman and Hopkinson were demonstrating in their studies at University College London that even comparatively small window areas could provide "...quality, modelling and contact with the outside" with light for visual work provided by artificial lighting. ${ }^{22}$ Jay was moved to express the opinion that most conventional approaches to lighting engineering- - based on daylight factor and lumens on the working plane"23 - were completely irrelevant to the design problems of the architects of the Gulbenkian and that better approaches could be drawn from theatrical practice.

Most interest seemed to be concerned with an integrated approach to lighting design. Ballin referred, in his Presidential Address of $1969,{ }^{24}$ to the growing importance of the "environmental approach" which he judged to impact both the commercial lighting designers attached to lighting companies and the nascent independent lighting designers.

A review ${ }^{25}$ of the lighting of a variety of offices, mainly from Germany and neighbouring countries, concluded that architects and specialists in building services and environmental control needed to collaborate closely. The installations were lit to startlingly high levels of at least 1000 lux and some installations at "more than twice this level are already in use and giving satisfactory service." ${ }^{26}$ Hopkinson commented that the installations seemed to be uniform and called for a "moderate level of building lighting combined with a high level of selective lighting on the work." 27 The assessment of these installations had not been able to take advantage of Cuttle's recently suggested concept of vector : scalar ratio for modelling.

Marsden, in cynical mode, declared that commercial lighting was "descending globally to the same level of harmless mediocrity, requiring rubber plants for salvation"28 and pointed to the need for more variety in lighting which had been suggested by Aldworth and Bridgers in their paper Design for Variety in Lighting. ${ }^{29}$

A useful catalogue of then current design methods for working interiors was provided by Marsden. ${ }^{30}$

The Jay/Cuttle method: A simple design method using a narrow range of luminaires of known intensity distribution used in a regular array.

The Utilization Factor/Glare Index method: Determining through the utilization factor (UF), how many luminaires are needed to provide a specific average illuminance in a regular array and checking that the glare index (GI) of the installation will not exceed the specified limit. 
The Designed Appearance method: Producing a predetermined luminosity distribution in an interior, the prescription of the target luminosities requiring considerable experience.

What of the windowless interior such as that experienced in various factory buildings? Collins and Plant had suggested that "...the effect the lighting has on its character will be much more critical in determining its acceptability by the occupants and the long-term effect of the environment on their efficiency and well-being than it will be in a conventional building." 31 Their scale model studies of a room with a selection of lighting installations were within a range of the 10:3:1 ratio that had been suggested by Hopkinson for the preferred luminances of task, immediate surround and general environment respectively, ${ }^{32}$ although Jay had pointed out that these ratios were not likely to be achieved in a normally lighted interior. This gave guidance to the designer in designing large-scale luminance patterns - referred to by Waldram as the 'gross luminance pattern' ${ }^{33}$ But Cuttle argued for designers to use the illumination vector and vector : scalar ratio for specifying the directional quality of the lighting. A chart (Figure $6)$, based on his researches, was suggested for "...normal design purposes." 34

\section{Energy saving}

Hunt claimed that (in multi-person offices) "...the daylight conditions at the beginning of the working day determined whether or not the artificial lighting was in use during the day." 35 Hunt's calculations of energy savings in a school space using photoelectric control of luminaire rows over a variety of day lengths claimed savings in a range from $20-60 \%$ of the full working year electricity consumption. ${ }^{36}$

Moving away from the current basis of uniform lighting, McKennan and Parry concluded from their experimental study that "... a task/background lighting scheme, where overall illumination levels are substantially reduced from normal uniform lighting, could be regarded favourably by office occupants providing the system was carefully designed to avoid practical problems." 37

Lighting was becoming to be felt a major component of the built environment with members of the lighting profession able to exert influence on the overall design of the environment. Collins believed that in the future:-

"...we shall be less concerned with recommending illuminances and more with recommending electrical loadings, so that improvements in standards will come about from improvements in design and control of lighting installations and in efficiency and performance of light sources and equipment, with no more, or perhaps even less loading than in the more efficient installations of today." 38

To save energy, in a context in which lighting accounted for about half the total annual cost of the [building] services, ${ }^{39}$ it was felt that horizontal plane illuminance could be reduced if the directionality of lighting could be controlled to provide a small 
improvement in contrast. This desired directionality of lighting could be provided by local lighting. ${ }^{40}$

Bell and Page argued that designers used descriptive words such as 'lively' or 'bright' to define the character of a space but at some point "...these ideas must be translated into a physical solution."41 and they noted that the wide variety of parameters that had been suggested were not well understood but instead most designers retreated to the safety of the average illuminance on the horizontal working plane. The Multiple Criterion Design method had been introduced in 1977. This was a technique to allow the designer to control the properties of a lighting installation to ensure compliance with a particular set of criteria e.g. wall illuminance ratio, ceiling illuminance ratio and vector/scalar ratio, in addition to horizontal illuminance and limiting glare index. ${ }^{42}$ However it was not widely used by practising designers because of the "...conceptually difficult and time consuming nature of the design process." ${ }^{43}$

Illuminance alone was useful in one regard. In an experimental study in a mockup art gallery space, based on subjective assessment, Loe et al. had proposed that paintings be illuminated at 2001x from good colour rendering lamps with a degree of nonuniformity of the light pattern. ${ }^{44}$ This raised the illuminance recommendation from the 150lx maximum illuminance for moderately sensitive objects and artwork that had been recommended in Thomson's influential book The Museum Environment. ${ }^{45}$

Finally there was Waldram's magisterial work on perspective for the lighting engineer (and the architect and town planner) to portray "...exactly the visual field." ${ }^{46} \mathrm{He}$ pondered the advantages of generating perspectives by computer with the main advantage being "...the possibility of changing the viewpoint..." ${ }^{47}$ but thought the whole process was time-consuming whereas his complex perspective view of Ely Cathedral (Figure 7) was produced in only 4 hours! ${ }^{48}$

\section{Innovative daylighting}

Loe et al. recommended that it was important for lighting designers to create a 'meaningful' light pattern. From their research studies they had isolated two independent factors which they called 'visual interest' and 'visual lightness' and that the "gloomy and dull"49 visual environment to be found in installations incorporating very low brightness louvre luminaires could be overcome by average luminance and maximum to minimum luminance recommendations.

Cuttle considered the appearance of architectural spaces in a discussion of Sumpner's principle - whereby the mean room surface illuminance is related to the direct component of illuminance and the area weighted average reflectance of all room surfaces. ${ }^{50} \mathrm{He}$ pointed out that there are perhaps two main situations of concern to designers. First, how well lit a room appears to be and second, the appearance of a specific object, or a group of objects, within a room. ${ }^{51}$ He recommended the use of Lynes' 
procedure (owing much to Waldram's Designed Appearance technique) for designing lighting in terms of relative surface illuminances and a formulation by Jay to generate desired object to background contrasts in architectural settings. ${ }^{52}$

Because of the renewed interest in daylighting, Littlefair pointed to the proposed architectural and engineering techniques to increase daylight availability-so-called "innovative daylighting". ${ }^{53} \mathrm{He}$ identified several developments (Figure 8) including:

- The light pipe - with sunlight collected by a 'heliostat' and distributed by an 'emitter'.

- Mirror systems - fixed or moveable highly reflective louvres.

- Prismatic systems - redirecting prismatic sheets.

- Light shelves - horizontal baffles set within the window to shade and redirect light.

An evaluation was made of the effectiveness of these techniques, with sunlight-only systems deemed inappropriate for the UK and a warning that these systems, however innovative, could not produce light - they could only redistribute that entering the system. $^{54}$

With the increasing pressure from conservators to preserve our cultural heritage, Cuttle suggested that moving to a process of "...limiting values of annual damage exposure based on current practice" should not be difficult to resolve and that the computerised cataloguing of items in a museum or gallery collection went hand-in-hand with computer control of environmental conditions to promote conservation. ${ }^{55}$

\section{Visualising light}

Ayers and Carter, ${ }^{56}$ in a fascinating review, considered the current state of development in remote source lighting. Such systems were composed of three components: source, light transport and emitter and the authors pointed out that development had been uneven in these components. They proposed that the overall efficiency of a 'typical' system would be of the order of $25 \%$ meaning that a system with a 30,000 lumen output source would deliver 7500 lumens $^{57}$ although the distribution of light from the emitter was the less well-developed aspect of the subject. Pinniger, in a comment, stated that if the light source was daylight then large amounts of usable light could be delivered by these systems albeit with architecturally significant prismatic tube elements of $300-400 \mathrm{~mm}$ diameter. ${ }^{58}$

On the 30th anniversary of Lighting Research and Technology, future trends in lighting were explored. Bodmann stated that architectural lighting "...is increasingly 
recognised as necessary for revealing the 'essentials' of the built environment, spaces, structures, materials and objects, according to their relevance and in relation to each other. ${ }^{159}$ However, Tammes struck a gloomier note predicting the "...re-energising of the schism..." between lighting engineering to comply with codes and a holistic design approach to create "...visual interest, stimulus and variety." ${ }^{60}$ Such a holistic framework had been suggested earlier by Loe and Rowlands ${ }^{61}$ incorporating, amongst others, lighting for visual function, lighting for visual amenity and lighting and architectural integration. Cuttle's description of cubic illumination as a key concept in a comprehensive system of applied photometry ${ }^{62}$ was fascinating in that it provided a toolkit which could be used by (mathematically sophisticated) designers to describe "...some sense of the dynamic visual effects..."63 as a viewer freely walks around a sculpture mounted at eye level.

Although there was disagreement about the precise nature of the lighting terminology employed, Cuttle welcomed the prospects of employing computation (such as the Radiance rendering program) in lighting design featured in a paper by Moeck which proposed that "...the desired visual impact is translated into...luminance contrast." 64

Stone welcomed the research by Loe et al. that seemed "...not only to support the spirit of but also to bring closer to reality...Hopkinson's proposals for a code of lighting based on luminance." A correspondence was suggested between the factors of 'visual interest' and 'visual lightness' with the appraisal dimensions of coherence, legibility, mystery and complexity that had been suggested by Kaplan and Kaplan but the technique was bedevilled by the necessity to define overall adaptation luminance. ${ }^{65}$

Cuttle contended that Waldram's Designed Appearance method was as relevant today as it was fifty years ago and urged the designer to develop a 'hierarchy of illuminance' - visual emphasis based on illuminance ratios in a method developed by Lynes. This obviated the need for referring to luminance/brightness scales. ${ }^{66}$

As the sophistication of lighting controls developed, what was the impact on the users of buildings? Moore, Carter and Slater undertook an opinion study of fourteen UK office buildings, seven equipped with user controls and seven without user controls. They found evidence that the installation without user controls had better conditions when judged in terms of conventional recommendations for task illuminance and luminance levels and ratios but that users viewed "...individual control more positively."67 They concluded that "...occupants prefer the ability to choose conditions rather than being forced to accept conditions chosen for them, even if these are objectively better." 68

Controls strategies could be applied to museums and galleries as well. CannonBrookes pointed out how difficult it was to gauge how well daylit galleries perform while meeting conservation standards. ${ }^{69}$ A selection of galleries (including the National Gallery and the Tate Gallery in London) had developed technological solutions to maintaining a constant level of daylight illuminance on the vertical display surface. He suggested that- 
because meeting conservation targets does not guarantee good viewing conditions - the relationship between the two needed to be re-established and an annotated checklist of criteria (Table 1) was provided to assist in developing strategies for daylit galleries. ${ }^{70}$

$\mathrm{Ng}$ addressed the problem of mega-cities and high density living rapidly becoming the norm in Asian cities. For such high-density residential sites (Figure 9) he proposed a simple design method ${ }^{71}$ for urban designers to use at the preliminary design stage which assessed average daylight factor in terms of vertical and horizontal obstruction and window glazing area. This was to allow the provision of better daylit interiors in these high-density residential blocks.

The linear atrium was coming into use as "...a communication route for larger developments of urban character." 72 They could be problematic in that ground floor rooms could receive little light while upper level rooms could be overlit with problems of solar glare - possible amelioration techniques were to vary glazing area with height and to vary glazing type (clear and reflective) with height. ${ }^{73}$

A validation of the Radiance lighting simulation system had been undertaken by Mardaljevic and the prediction of internal illuminance to a high degree of accuracy was now possible for a range of realistic sky conditions. He indicated that the system had been used to visualise a range of architectural projects and that it was flexible enough to be used at all stages of the design process. ${ }^{74}$ In discussion, the author of the program (Ward) emphasised that Radiance was "... a calculation tool first and a rendering package second." 75 and that the realistic images were the effect of a good underlying physical model.

\section{Circadian lighting}

As we reach the present day, Cuttle is now proposing a design procedure based on Mean Room Surface Exitance (MRSE) and Target/Ambient Illumination Ratio (TAIR). These two metrics relate to two lighting design criteria: ${ }^{76}$

- Perceived Adequacy of Illumination: The level of illumination that is judged just sufficient to make a space appear acceptably bright for the activity it houses.

- Illumination Hierarchy: The distribution of illumination to express the visual significance of the activities or the contents of spaces.

This procedure is proposed to overcome, on the one hand, lighting designers and engineers preoccupied with horizontal working plane illuminances and, on the other, those designers interested in the overall appearance of the space and local emphasis and modelling. But Boyce and Smet, discussing the outcomes of an LRT Symposium on the 
current state of lighting metrics point out that Cuttle's metric had been developed for electric lighting only and that daylight from windows inevitably produces a nonuniform light distribution. ${ }^{77}$ And in an interesting aside, Cuttle encourages the lighting professional to move into the 'third stage' of the lighting profession interacting with architects and designers to:-

"...think of the room that they are to illuminate as a secondary luminaire which illuminates the eye. Just as they examine the optical properties of the primary sources, whether luminaires or windows, in order to understand how they will distribute flux within the room, so they may examine the optical properties of room surfaces to understand how they will interact with the distribution of direct flux and present light to the eye." 78

Leslie and his co-authors favour a 'daylighting dashboard ${ }^{19}$ to allow evaluation of daylighting potential at the conceptual design stage in terms of eight components of a framework. Of interest is the Circadian Stimulus (CS) component to encourage sufficient light to promote circadian stimulation. The dashboard has been used to evaluate a variety of classroom envelopes with a 'green-amber-red' warning system to indicate to architects where further consideration of the design needs to be made.

The practical implications of a study by Veitch et al. are that carefully designed direct-indirect lighting systems, "...particularly those offering control over the direct component..." will meet the twin goals of high task visibility and favourable appraisals of lighting quality. ${ }^{80}$

The illumination of fine art by LEDs is the future and Csuti et al. have devised a quartet of LED spectra — based on red, green, blue and white — giving an additive mixture which has been optimised for viewing paintings (at 3500K) (Figure 10). This produces the impression of colours in the paintings as if they had been painted in daylight and is based on setting the currents of the four LED channels. ${ }^{81}$

Zhai et al. have found that "...lighting within the CCT range $2850-4000 \mathrm{~K}$ and $a$ moderate illuminance range of 200-800 lux is considered to be comfortable or pleasing for LED lighting of paintings in museums." 82

But display is not confined to the gallery or museum. Schielke maintains that "Alone, interior lighting may not have the potential to explicitly communicate a specific brand name but it could facilitate sending a specific brand image." ${ }^{83}$ In responding to the question as to whether lighting plays a significant role in creating ambience or atmosphere, where atmosphere dimensions were defined as cosiness, liveliness, tenseness and detachment, Custers et al. found that the lighting attributes of brightness decreased perceived cosiness and increased perceived tenseness and that glare and sparkle contributed to the perceived liveliness of fashion stores. ${ }^{84}$ In more recent work Schielke 
and Leudesdorff have pointed to the primacy of light patterns and suggested that designers "...would benefit from a strategy, which is not primarily focused on brightness but on spatial pattern based on lighting to compose a specific corporate visual identity." 85

In a review of lighting for dementia, Torrington and Tregenza point out that their lighting recommendations could usefully be applied to any residential context e.g. hotels or apartment blocks. The aim in these spaces is to achieve a consistency between the use of the space and its physical characteristics — synomorphy. ${ }^{86}$ They state:-

"Lighting is clearly central to this: lamps, luminaires and windows, both in their characteristics as objects and in the patterns of light they produce, have strong associations with the perceived nature of particular places. ${ }^{187}$

Dick is interested in defining the limits or thresholds to artificial light at night — pointing to the need for all organisms to experience periods of darkness (scotobiology) — and claims that it is now appropriate to review the use of artificial light at night to reduce impacts on humans, wildlife and to reduce energy costs. ${ }^{88}$

\section{Endpiece}

It is to the great credit of all those practitioners and researchers featured in the pages of Lighting Research and Technology that they have maintained enthusiasm for exploring the interaction of light, people and architecture. My sense is that architects are still primarily motivated by daylight and, increasingly, more formal considerations of architectural typology and regard the provision of artificial lighting as a slightly tiresome necessity. This perhaps explains why, in the survey of architectural drivers presented here, the relationship with lighting research and application appears hazy. It seems clear that in the early years of Lighting Research and Technology, in keeping with the social concerns of the time, great store was set by the contribution that environmental science could make to the provision of comfortable, engaging environments which was perhaps lost in later years. The current ongoing research into non-image forming aspects of light now offers the enticing prospect of incorporating such findings into the design of contemporary buildings as a counterpoint to lighting design based primarily on visual appearance.

Over the last fifty years, lighting education has moved from a branch of physics to a form of engineering and latterly as part of environmental design. In the UK in 1912, a number of courses were offered on photometry. Post war, the Borough Polytechnic (now 
South Bank University) offered courses on illumination engineering and in 1987, UCL set up its specialist graduate course in lighting, the MSc Light and Lighting. These national and other international courses allow architects, designers and engineers to develop their understanding and skills in lighting design.

It has been difficult to capture the multi-strand nature of architectural development over the past fifty years but it has been heartening to describe the many contributions that all those engaged in lighting research and application have made to lighting design.

There are many tools that have been developed - multiple criterion design, luminance pattern, perceived adequacy of illumination - but they are just tools. I shall leave the last word to Joe Lynes who wrote wisely:-

"A good lighting engineer will determine afresh for each project what character the lighted space should express. Photometric criteria then take their rightful place as tools for defining and achieving the appropriate pattern of light and shade." 89

\section{Declaration of conflicting interest}

The author declares that there is no conflict of interest.

\section{Funding}

The author received no financial support for the research, authorship or publication of this article.

\section{Acknowledgement}

The author would like to thank David Loe for providing useful additional insights and an unnamed reviewer whose comments served to clarify the text.

\section{References}

1 Fazio M, Moffett M, Wodehouse L. A World History of Architecture. London: Laurence King Publishing, 2009, p.517. 
2 Watkin D. A History of Western Architecture. London: Laurence King Publishing, 2011, p.652.

3 Cited in Webb M. Architecture in Britain Today. Middlesex: Country Life Books, 1969, p.40.

4 Ibid. p.40.

5 Fazio et al. op. cit. pp. 560-564.

6 Foster M (Ed.). The Principles of Architecture: Style, Structure and Design. London:

New Burlington Books, 1983, p.107.

7 Plummer H. The Architecture of Natural Light. London: Thames and Hudson, 2009, pp. $126-129$.

8 Fazio et al. op. cit. p.542.

9 The Berlin Package (English translation). Munich: arsEdition, 2001, pp. 5-7.

10 Watkin D. op.cit. pp. 666-667.

11 Phillips D. Daylighting: Natural Light in Architecture. London: Architectural Press, 2004, pp. 72-75.

12 Lacy B (Ed.) 100 Contemporary Architects: Drawings and Sketches. London: Thames and Hudson, 1991, pp 74-75.

13 Watkin D. op.cit. pp. 681-682, 699.

14 Fazio et al. op.cit. p.545.

15 Watkin D. op. cit. p.675.

16 Phillips D. The Lit Environment. London: Architectural Press, 2002, p.33.

17 Watkin D. op. cit. p.670.

18 Ibid. p.700.

19 Fazio et al. op.cit. pp. 564-565.

20 Watkin D. op.cit. pp. 697-698. 
21 Ribeiro JS, Allen WA, De Amorim M. Lighting of the Calouste Gulbenkian Museum. Lighting Research and Technology 1971; 3: 79-98.

22 Ne'eman E, Hopkinson RG. Critical minimum acceptable window size: A study of window design and provision of view. Lighting Research and Technology 1970; 2: 17-27.

23 Ribeiro et al. op. cit. p.97.

24 Ballin HH. The lighting designer. Lighting Research and Technology 1969; 1: 1-7.

25 Steck B. European practice in the integration of lighting, air conditioning and acoustics in offices. Lighting Research and Technology 1969; 1: 8-23.

26 Ibid. p.19.

27. Ibid. p.21.

28. Marsden AM. What do we want from our lighting? Lighting Research and Technology 1972; 4: 139-150.

29. Aldworth RC, Bridgers DJ. Design for variety in lighting. Lighting Research and Technology 1971; 3: 8-23.

30. Marsden AM. op. cit. p. 146.

31. Collins JB, Plant CGH. Preferred luminance distribution in windowless spaces. Lighting Research and Technology 1971; 3: 219-231.

32. Ibid. p.230.

33. Waldram JM. Studies in interior lighting. Transactions of the Illuminating Engineering Society (London) 1954; 19: 95-124.

34. Cuttle C. Lighting patterns and the flow of light. Lighting Research and Technology 1971; 3: 171-189.

35. Hunt DRG. Improved daylight data for predicting energy savings from photoelectric controls. Lighting Research and Technology 1979; 11: 9-23.

36. Ibid. p.21.

37. McKennan GT, Parry CM. An investigation of task lighting for offices. Lighting Research and Technology 1984; 16: 171-186.

38. Collins JB. The illuminating engineer in a changing world. Lighting Research and Technology 1977; 9: 1-10 
39. Ibid. p.8.

40. Ibid. p.8.

41. Bell RI, Page RK. The need for a unified approach to interior lighting design parameters. Lighting Research and Technology 1981; 13: 49-57.

42. Illuminating Engineering Society. IES Technical Report No. 15 The Multiple Criterion Design Method. London: IES, 1977: p.6.

43. Price WA cited in Carter DJ. A computer aid to multiple criterion design. Lighting Research and Technology 1981; 13: 153-157.

44. Loe DL, Rowlands E, Watson NF. Preferred lighting conditions for the display of oil and watercolour paintings. Lighting Research and Technology 1982; 14: 173-192.

45. Thomson G. The Museum Environment. London: Butterworths, 1978.

46. Waldram JM. A manual of perspective for lighting engineers. Lighting Research and Technology 1982; 14: 65-101.

47. Ibid. p. 99.

48. Ibid. p. 99.

49. Loe DL, Mansfield KP, Rowlands E. Appearance of lit environment and its relevance in lighting design: Experimental study. Lighting Research and Technology 1994; 26: 119133.

50. Cuttle C. Sumpner's principle: A discussion. Lighting Research and Technology, 1991; 23: 99-106.

51. Ibid. p. 100 .

52. Ibid. p. 100, 102.

53. Littlefair PJ. Innovative daylighting: Review of systems and evaluation methods. Lighting Research and Technology 1990; 22: 1-17.

54. Ibid. p. 13.

55. Cuttle C. Lighting works of art for exhibition and conservation. Lighting Research and Technology 1988; 20: 43-53. 
56. Ayers MJ, Carter D. Remote source electric lighting. Lighting Research and Technology 1995; 27: 1-15.

57. Ibid. p. 12.

58. Ibid. p. 14.

59. Cannon-Brookes S (Ed.) Future trends in lighting. Lighting Research and Technology 1998; 30: 63-68.

60. Ibid. p. 64.

61. Loe DL, Rowlands E. The art and science of lighting: A strategy for lighting design. Lighting Research and Technology 1996; 28: 153-164.

62. Cuttle C. Cubic illumination. Lighting Research and Technology, 1997; 29: 1-14.

63. Ibid. p. 11.

64. Moeck M. Lighting design based on luminance contrast. Lighting Research and Technology, 2000; 32: 55-63.

65. Loe DL, Mansfield KP, Rowlands E. A step in quantifying the appearance of a lit scene. Lighting Research and Technology 2000; 32: 213-222.

66. Cuttle C. Brightness, lightness and providing 'a preconceived appearance to the interior'. Lighting Research and Technology 2004; 36: 201-216.

67. Moore T, Carter DJ, Slater AI. A study of opinion in offices with and without user controlled lighting. Lighting Research and Technology 2004; 36: 131-144.

68. Ibid. p. 142.

69. Cannon-Brookes S. Daylighting museum galleries: A review of performance criteria. Lighting Research and Technology 2000; 32: 161-168.

70. Ibid. p. $166-167$.

71. Ng E. A simplified daylighting tool for high-density urban residential buildings. Lighting Research and Technology 2001; 33: 259-272.

72. Matusiak B, Aschehong Ø, Littlefair P. Daylighting strategies for an infinitely long atrium: An experimental evaluation. Lighting Research and Technology 1999; 31: 23-34.

73. Ibid. p. 33-34. 
74. Mardaljevic J. Validation of a lighting simulation program under real sky conditions. Lighting Research and Technology 1995; 27: 181-188.

75. Ibid. p. 188.

76. Cuttle C. A new direction for general lighting practice. Lighting Research and Technology 2013; 45: 22-39.

77. Boyce PR, Smet KAG. LRT Symposium 'Better metrics for better lighting'-a summary. Lighting Research and Technology 2014; 46: 619-636.

78. Cuttle C. Towards the third stage of the lighting profession. Lighting Research and Technology 2010; 42: 73-90.

79. Leslie RP, Radetsky LC, Smith AM. Conceptual design metric for daylighting. Lighting Research and Technology 2012; 44: 277-290.

80. Veitch JA, Newsham GR, Boyce PR, Jones CC. Lighting appraisal, well-being and performance in open-plan offices: A linked mechanisms approach. Lighting Research and Technology 2008; 40: 133-151.

81. Csuti P, Fáy A, Schanda J, Szabó F, Tátrai V. Colour fidelity for picture gallery illumination, part 2: Test sample selection-museum tests. Lighting Research and Technology 2015; 47: 529-530.

82. Zhai QY, Luo MR, Liu XY. The impact of illuminance and colour temperature on viewing fine art paintings under LED lighting. Lighting Research and Technology 2015; 47: 795-809.

83. Schielke T. Light and corporate identity: Using lighting for corporate communication. Lighting Research and Technology 2010; 42: 285-295.

84. Custers PJM, de Kort YAW, IJsselsteijn WA, de Kruiff ME. Lighting in retail environments: Atmosphere perception in the real world. Lighting Research and Technology 2010; 42: 331-343.

85. Schielke T, Leudesdorff M. Impact of lighting design on brand image for fashion retail stores. Lighting Research and Technology 2015; 47: 672-692.

86. Torrington JM, Tregenza PR. Lighting for people with dementia. Lighting Research and Technology 2007; 39: 81-97.

87. Ibid. p. 92.

88. Dick R. Applied scotobiology in luminaire design. Lighting Research and Technology 2014; 46: 50-66. 
89. Cayless MA, Marsden AM (Eds.) Lamps and Lighting. London: Edward Arnold, 1983, p.43.

\section{Figure captions}

Figure 1. University of Leicester (Engineering, 1964) (James Stirling). Available from https://commons.wikimedia.org/wiki/File:Leicester_University_Engineering_Building.jp $\mathrm{g}$

Figure 2. L'Institute du Monde Arabe (Jean Nouvel). Available from https://fr.vikidia.org/wiki/Fichier:IMA face_sud_moucharabiehs.jpg

Figure 3. Artist's impression of Potsdamer Platz, Berlin. Available from https://commons.wikimedia.org/wiki/File\%3ALa_Potsdamerplatz_(Berlin)_(2704060441 .j.jpg

Figure 4. Guggenheim Museum, Bilbao (Frank Gehry). Available from https://commons.wikimedia.org/wiki/File:Guggenheim_Museum,_Bilbao,_July_2010_1 1).JPG

Figure 5. CCTV Headquarters, Beijing (Rem Koolhaas) Available from http://daviddanikowski.com/pic-gallery/

Figure 6. Assessing flow of light through vector : scalar ratio [Adapted from Cuttle C. Ibid. Fig. 16, p.183.]

Figure 7. Perspective drawing of Ely Cathedral (JM Waldram) [Adapted from Waldram JM. Ibid. Fig. 35, p.82.]

Figure 8. A variety of light pipes [Adapted from Littlefair PJ. Ibid. Fig. 3, p.2.] 
Figure 9 Example of high-density residential block plan in Hong Kong [Adapted from Ng E. Ibid. Fig. 4, p.264.]

Figure 10. Spectra of four-component LEDs and optimised composite spectrum [Adapted from Csuti et al. Ibid. Fig. 8, p.529.] 
Table 1. Criteria for daylight galleries

\begin{tabular}{l} 
Maximum annual light dosage \\
\hline Minimum display illumination \\
\hline Range of daylight \\
\hline Preferred proportion of daylight in display areas \\
\hline Preferred colour temperature \\
\hline Uniformity of illumination across exhibits \\
\hline Contrast of exhibit to background \\
\hline Daylight management and control
\end{tabular}




\section{FIGURES}

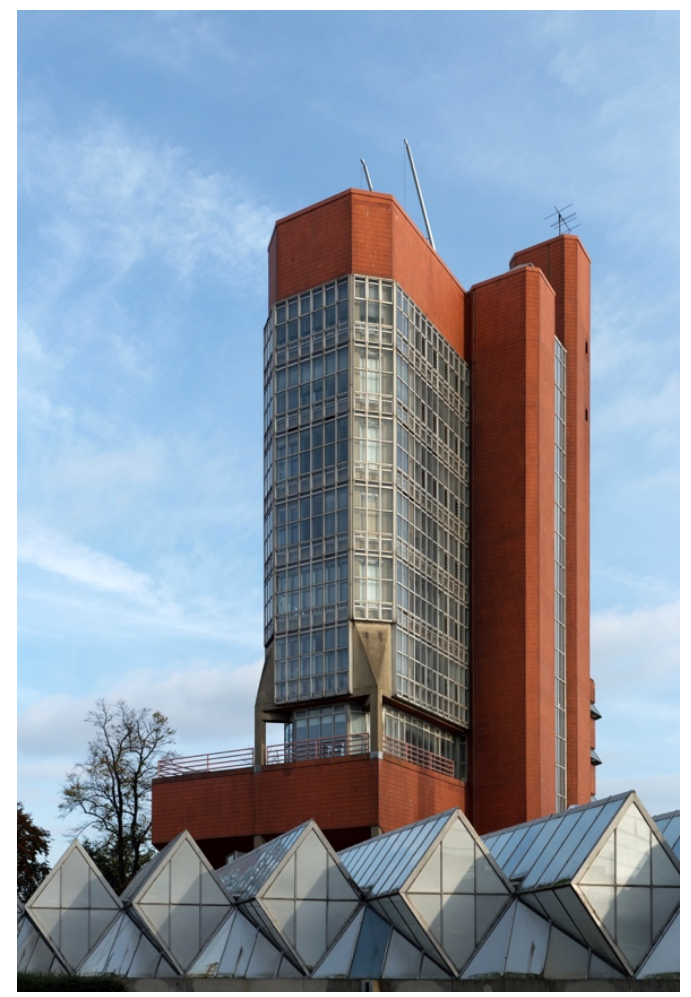

Figure 1. University of Leicester (Engineering, 1964) (James Stirling). Available from https://commons.wikimedia.org/wiki/File:Leicester_University_Engineering_Building.jp 


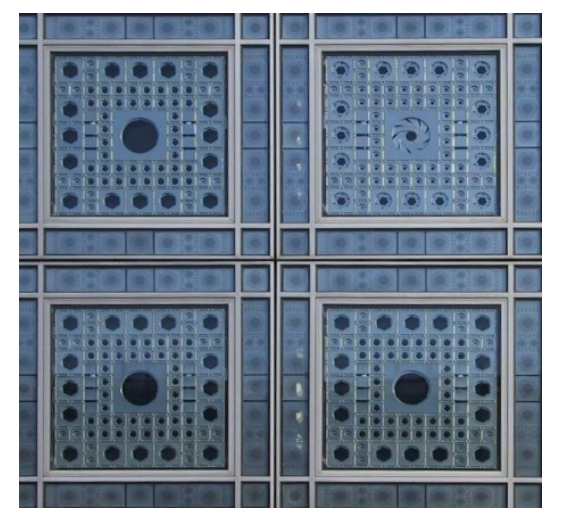

Figure 2. L'Institute du Monde Arabe (Jean Nouvel). Available from https://fr.vikidia.org/wiki/Fichier:IMA_face_sud_moucharabiehs.jpg

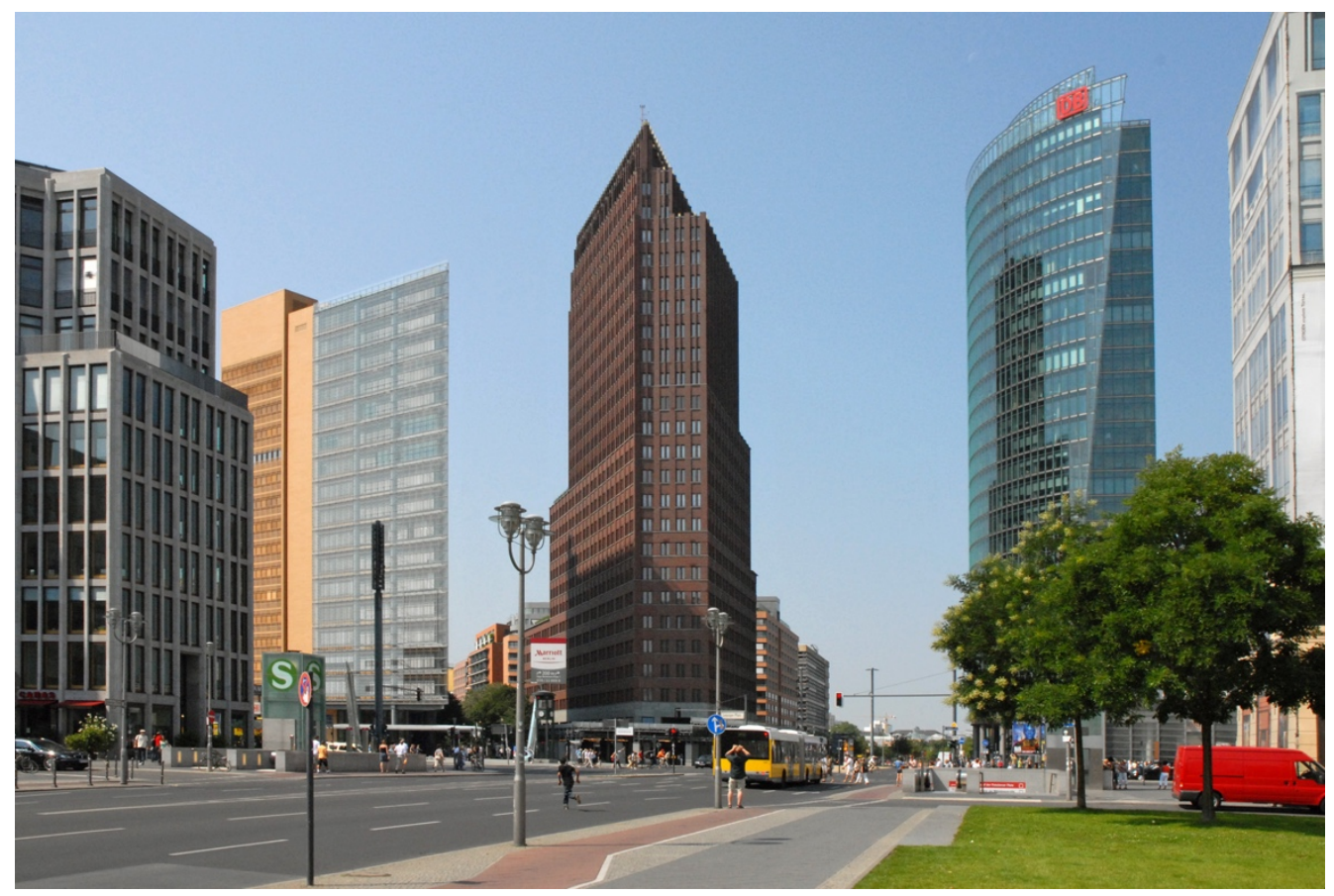

Figure 3. Artist's impression of Potsdamer Platz, Berlin. Available from https://commons.wikimedia.org/wiki/File\%3ALa_Potsdamerplatz_Berlin)_(2704060441).jpg 


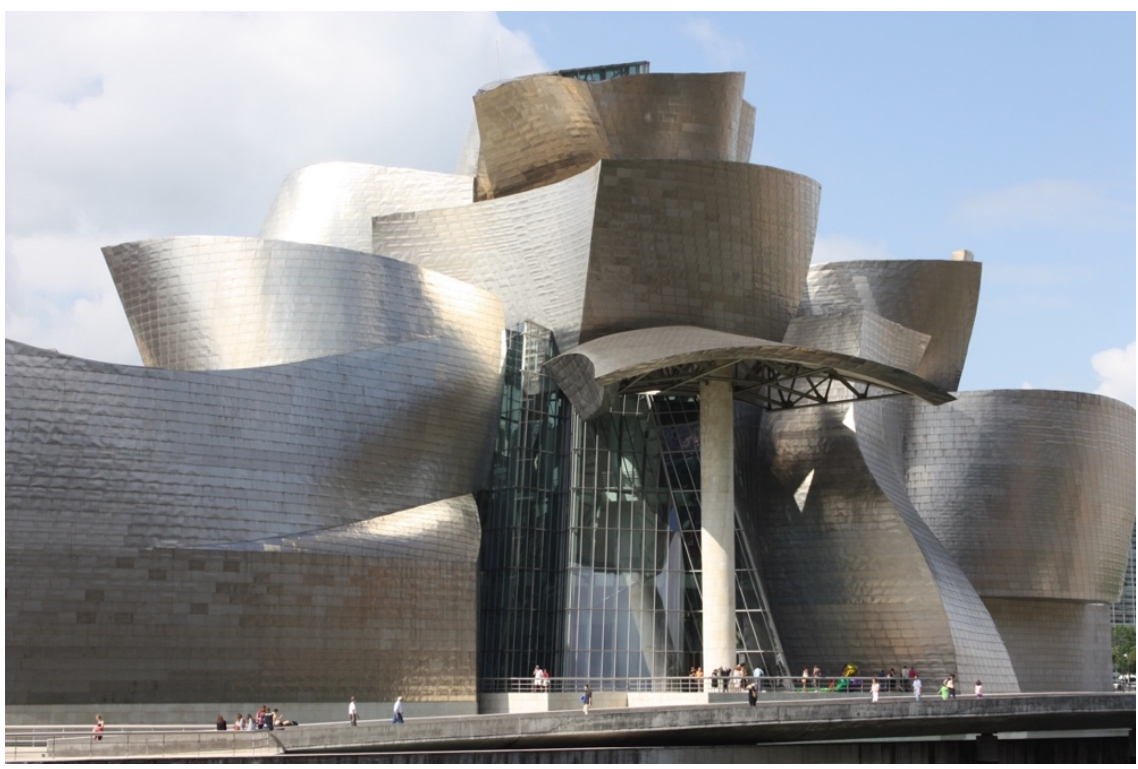

Figure 4. Guggenheim Museum, Bilbao (Frank Gehry). Available from https://commons.wikimedia.org/wiki/File:Guggenheim_Museum,_Bilbao,_July_2010_(11).JPG

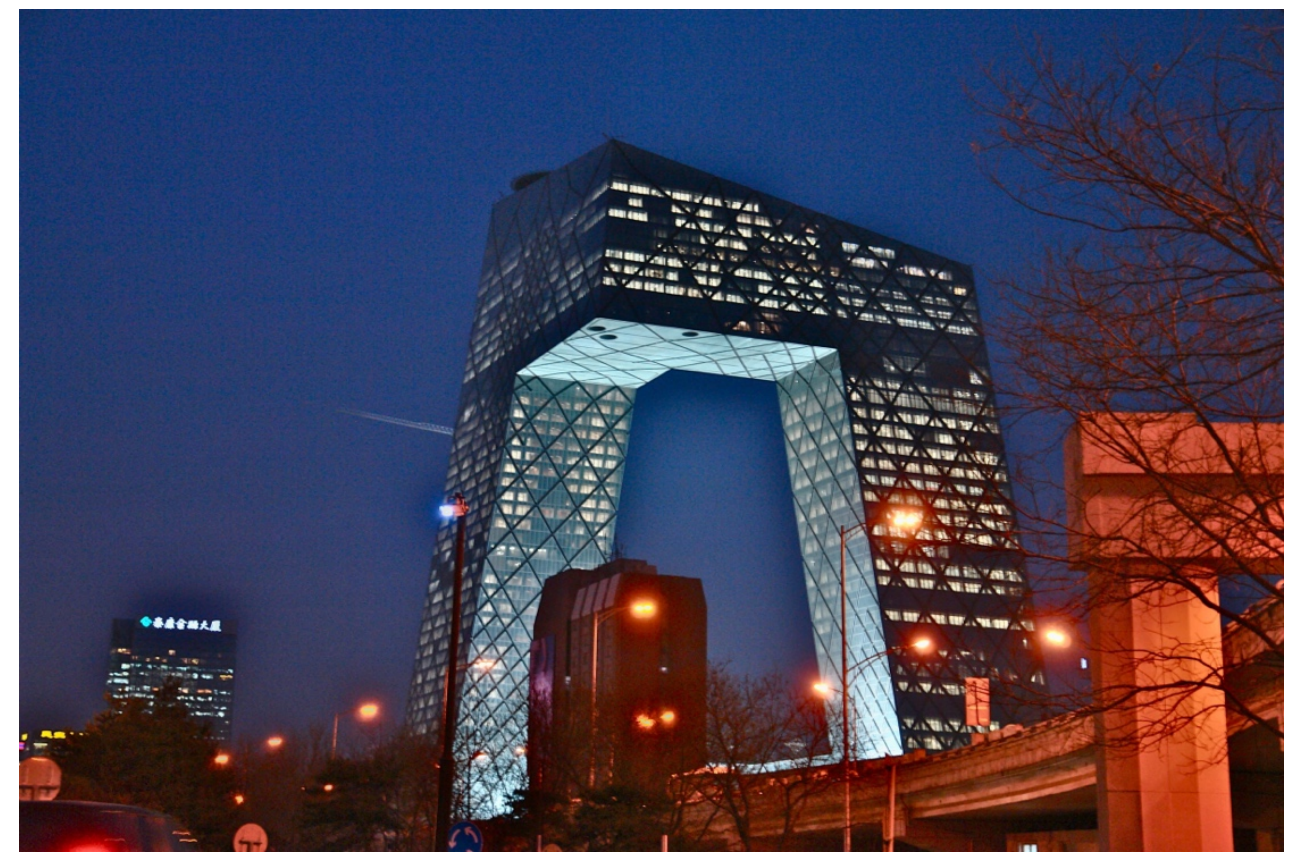

Figure 5. CCTV Headquarters, Beijing (Rem Koolhaas). Available from http://daviddanikowski.com/pic-gallery/ 


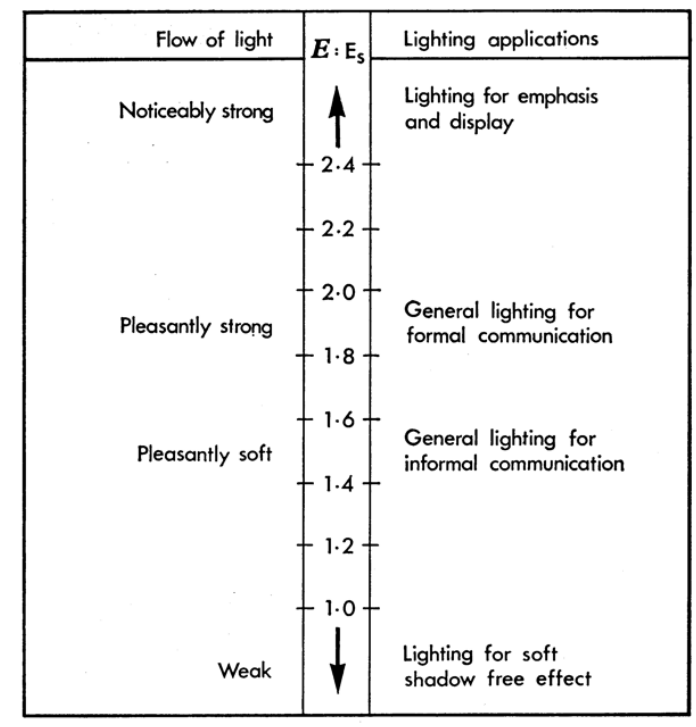

Figure 6. Assessing flow of light through vector : scalar ratio [Adapted from Cuttle C. Ibid. Fig. 16, p.183.]

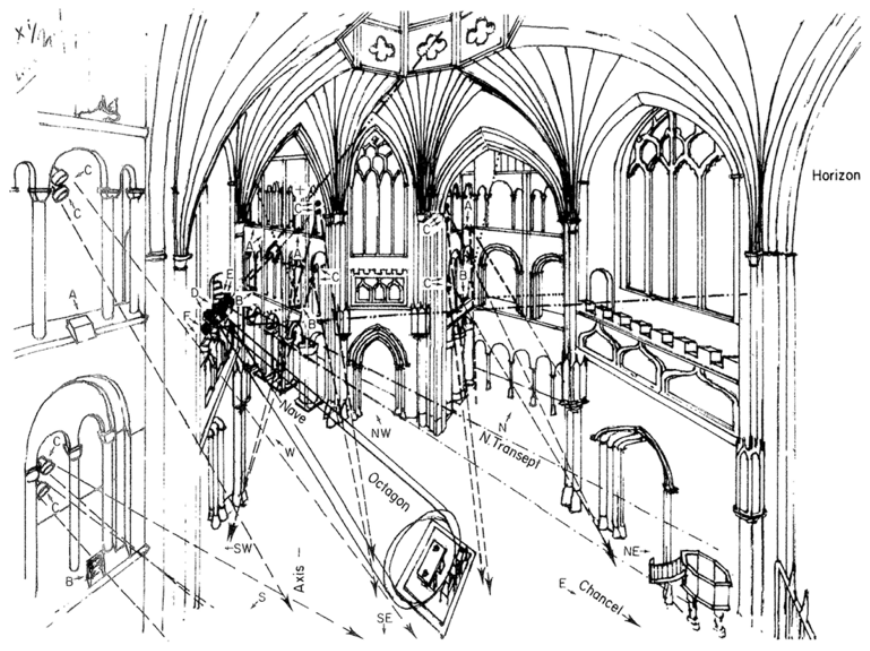

Figure 7. Perspective drawing of Ely Cathedral (J M Waldram) [Adapted from Waldram JM. Ibid. Fig. 35, p.82.] 


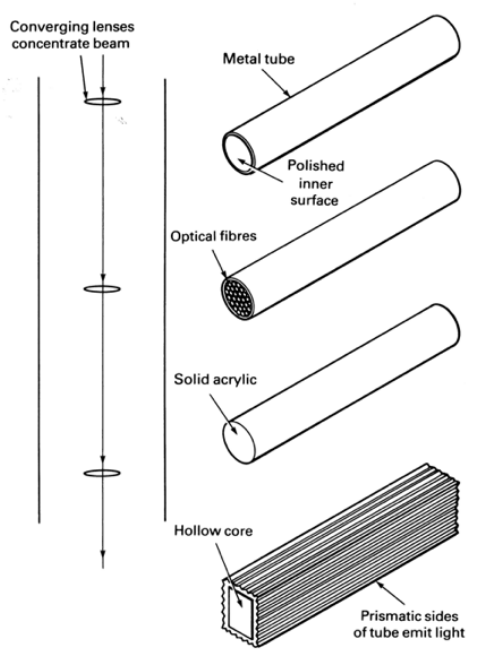

Figure 8. A variety of light pipes [Adapted from Littlefair PJ. Ibid. Fig. 3, p.2.]

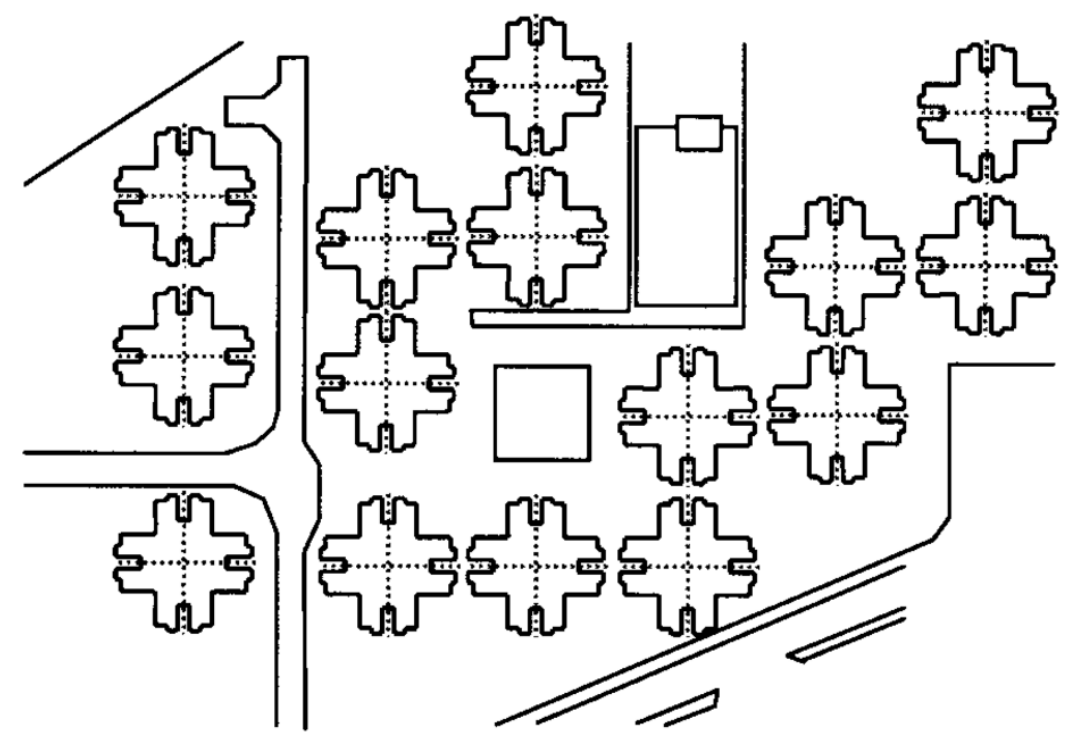

Figure 9. Example of high-density residential block plan in Hong Kong [Adapted from Ng E. Ibid. Fig. 4, p.264.] 


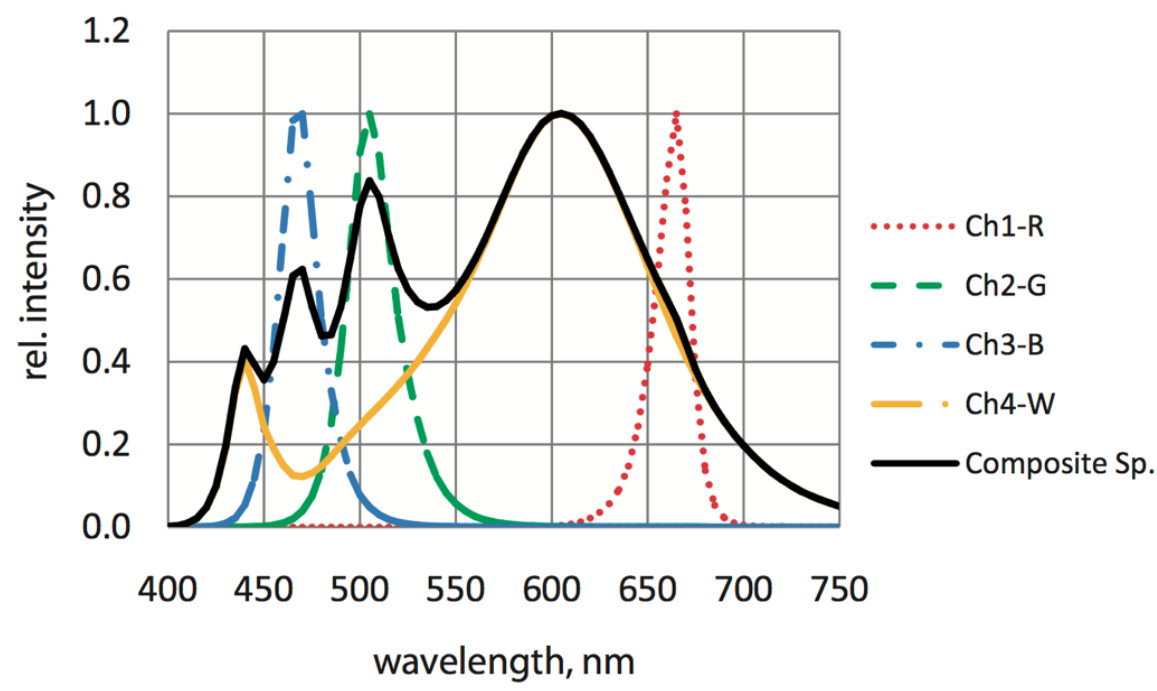

Figure 10. Spectra of 4-component LEDs and optimised composite spectrum [Adapted from Csuti et al. Ibid. Fig. 8, p.529.] 